\section{Can neck circumference predict insulin resistance in older people? A cross-sectional study at primary care in Brazil}

\section{A circunferência do pescoço prediz a resistência insulínica no idoso? Um estudo transversal na atenção primária no Brasil}

\author{
¿La circunferencia del cuello predice la \\ resistencia a la insulina en el anciano? Un estudio \\ transversal en la atención primaria en Brasil
}

Maria Auxiliadora Nogueira Saad 1

Maria Luiza Garcia Rosa 2

Giovanna Balarini Lima 1

Rubens Antunes da Cruz Filho 1

doi: 10.1590/0102-311X00060916

\begin{abstract}
This study focused on the correlation between neck circumference and other anthropometric measurements and cardiovascular risk factors and insulin resistance in the elderly in Niterói, Rio de Janeiro State, Brazil. This was a cross-sectional study in 411 patients seen in primary care. Anthropometric measurements including neck circumference, body mass index (BMI), waist circumference (WC), and waist-hip ratio (WHR) were recorded. Bioelectrical impedance analysis (BIA) estimated the percentage of total body fat (\%TBF). Insulin resistance was estimated by HOMA-IR (homeostasis model assessment IR index). The data were analyzed by the Mann-Whitney test and the correlation between numerical variables by Spearman's test. Receiver operating characteristic (ROC) was used to assess the anthropometric measurements' predictive capacity to diagnosis insulin resistance. Neck circumference was positively correlated with WC, BMI, WHR, \%TBF, and HOMA-IR in both sexes. In women, neck circumference showed higher AUC (area under the curve) for insulin resistance. In men, WC showed higher AUC, followed by BMI and neck circumference. The current study in Southeast Brazil suggests that neck circumference can predict insulin resistance, an important marker of cardiovascular risk in the elderly population treated in primary care.
\end{abstract}

Anthropometry; Cardiovascular Diseases; Insulin Resistance; Aged

\section{Correspondence}

M. A. N. Saad

Rua Ary Parreiras 60, apto. 602, Niterói, RJ 24230-320, Brasil. auxiliadorasaad@gmail.com

1 Faculdade de Medicina da Universidade Federal Fluminense, Niterói, Brasil.

2 Instituto de Saúde Coletiva, Universidade Federal Fluminense, Niterói, Brasil. 


\section{Introduction}

Obesity has become epidemic all over the world, which is a cause of concern, since it is a public health problem related to cardiovascular diseases, metabolic syndrome, cancer, and other comorbidities. Moreover, in older persons, obesity can exacerbate the age-related decline in physical function and lead to frailty 1.

Upper-body distribution of fat is more predictive of metabolic and cardiovascular diseases than whole body obesity. Body mass index (BMI), a traditional anthropometric marker used in the majority of the epidemiological studies 2,3,4, is not the best method to evaluate central obesity 5,6,7. Computed tomography is the most accurate method to measure body fat, specifically visceral fat (VF), however, high cost and radiation exposure limit its use in clinical practice 8 .

After the age of 60, modifications in the body began to be noticed, such as composition with lean mass reduction and increase of fat mass, which tends to be redistributed with advancing age toward more VF 9. As a result, the anthropometric measures of central adiposity, such as BMI or abdominal circumference may not be accurate in older people 10. Therefore, is of great interest to find a simple and practical anthropometric measures of central obesity for that group. Neck circumference (NC), a simple and alternative anthropometric measure, was proposed as an index of central obesity. NC is associated with other cardiovascular risk factors, such as dyslipidemia, arterial hypertension, hyperuricemia, and insulin resistance (IR) 11,12,13.

To date, there are no published epidemiological data on the clinical significance of NC among individuals over 60 years old in Brazil.

Therefore, the aim of this study was to investigate the correlation of NC, other anthropometric measures, and body composition analysis with cardiovascular risk factors and insulin resistance in individuals aged over 60 years attending a primary care center.

\section{Methods}

This cross-sectional study was performed at a Geriatric and Internal Medicine Outpatient Clinic, a primary care center, in the city of Niterói, State of Rio de Janeiro, Brazil, including 411 individuals who visited the Outpatient Clinic for any reason from March 2011 to March 2013. All participants signed an informed consent form. The study protocol was approved by the Ethics Committee of the Medical School of Universidade Federal Fluminense (0183.0.258.10).

Exclusion criteria were: clinical or laboratory evidence of cardiac, renal, or liver disease, goiter or other neck lesions, severe cognitive deficits, or individuals using corticosteroids or immunosuppressants.

All the subjects underwent a detailed physical examination. Blood pressure was measured at the left arm, with the subjects sitting after five minutes of rest, using a calibrated automatic sphygmomanometer (OMRON HEM 742INT; OMRON Healthcare, Bannockburn, USA). The same researcher performed anthropometrical measures, while the subjects were wearing light clothes and no shoes. Weight and height were measured using a calibrated anthropometric scale (Filizola, São Paulo, Brazil) with capacity for $150 \mathrm{~kg}$. BMI was calculated as weight (in kilograms) divided by the square of the height (in meters) $\left(\mathrm{kg} / \mathrm{m}^{2}\right)$. Circumferences were measured using an inelastic tape (SANNY, São Paulo, Brazil). Waist circumference (WC) was measured at the midpoint between the lowest rib and the iliac crest, with the patient standing and at the end of an exhalation. Hip circumference (HC) was measured at the widest point between the waist and the thigh. Waist-to-hip ratio (WHR) was calculated by dividing WC by HC. Neck circumference was measured at the base of the neck, below the laryngeal prominence, with the subject standing upright, looking straight ahead, with shoulders down.

The percentage of total body fat (\%TBF) was assessed by a tetrapolar bioimpedance device (BIA) (Model 310, RJL; Biodynamics Corp., Seattle, USA), according to the protocol established by Lukasky et al. 14 .

Blood samples were obtained after a $12 \mathrm{~h}$ overnight fast. Fasting glucose, total cholesterol (TC), high-density lipoprotein cholesterol (HDL-c), triglycerides (TG), and uric acid were measured by commercial kits (Labtest, Belo Horizonte, Brazil). Low-density lipoprotein cholesterol (LDL-c) was 
estimated by Friedewald equation. Serum insulin concentrations were measured by electrochemiluminescence (ELECSYS; Roche, Tokyo, Japan).

Insulin resistance was assessed using the homeostasis model assessment IR index (HOMA-IR), which was calculated using the following formula: HOMA-IR $=$ [fasting glucose $(\mathrm{mmol} / \mathrm{L}) \mathrm{x}$ fasting insulin $(\mu \mathrm{U} / \mathrm{L})] / 22.5$. Insulin resistance was defined by a HOMA-IR $>2.71$, which is the cut-off value determined for the Brazilian population, for both sexes 15.

\section{Statistical analyses}

Analyses were performed using IBM SPSS version 21.0 for Windows (IBM Corp., Armonk, USA). All data were analyzed and reported by sex, as fat metabolism is different between sexes due to the regional fat distribution 16,17. Normality was verified using the Shapiro-Wilk test. The results are presented as medians with interquartile range for continuous variables. Associations between continuous variables and sex were determined by means of the Mann-Whitney U test. The Spearman correlation test (simple and partial) was adopted and adjusted for age and the diagnosis of diabetes. The correlation between variables was classified according to the categorization by Dancey \& Reidy 18 . Receiver operating characteristic (ROC) curves were constructed to evaluate the performance of anthropometric parameters in order to identify insulin resistance. The areas under ROC curves (AUC) were calculated using a range of $95 \%$. P-values $<0.05$ were considered statistically significant.

\section{Results}

The study group consisted of 411 subjects (304 women and 107 men) with a mean age of 70 years. Age, BMI, systolic blood pressure (SBP), TG, fasting blood glucose, fasting insulin, and HOMA-IR were not significantly different between the male and female groups. Women had a significantly greater percentage of \%TBF, higher TC, and HDL-c, but lower WC, NC, diastolic blood pressure (DBP), and uric acid (Table 1).

Considering the anthropometric measures, NC was positively correlated with WC $(\mathrm{r}=0.69$ and $\mathrm{r}=0.66 ; \mathrm{p}<0.01)$, BMI $(\mathrm{r}=0.71$ and $\mathrm{r}=0.72 ; \mathrm{p}<0.01)$ and $\mathrm{WHR}(\mathrm{r}=0.45$ and $\mathrm{r}=0.27 ; \mathrm{p}<0.01)$ in men and women, respectively. Concerning the body composition analysis, a moderate correlation was observed between NC and \%TBF ( $r=0.42$, for men and $\mathrm{r}=0.54$, for women; $\mathrm{p}<0.01)$. Regarding fasting insulin $(\mathrm{r}=0.49$ and $\mathrm{r}=0.46 ; \mathrm{p}<0.01)$ and HOMA-IR $(\mathrm{r}=0.44$ and $\mathrm{r}=0.47 ; \mathrm{p}<0.01)$ in men and women, respectively, NC also showed moderate correlation. However, NC showed a weak correlation with fasting blood glucose $(\mathrm{r}=0.22 ; \mathrm{p}<0.01)$, TG $(\mathrm{r}=0.26 ; \mathrm{p}<0.01)$ and uric acid $(\mathrm{r}=0.28$; $\mathrm{p}<0.01$ ) in women. The correlation between NC and HDL-c was negative in both sexes (Table 2).

The AUC values for different anthropometric measures were statistically significant. In women, NC presented the largest AUC for IR, which is similar to WC. However, in men, WC showed the largest AUC, followed by BMI and NC (Figure 1). Using the ROC curve analysis, NC $\geq 39.4 \mathrm{~cm}$ for men and $\geq 33.7 \mathrm{~cm}$ for women were determined to be the best cut-off values for identifying subjects with IR with $67.3 \%$ sensibility for men and $66.9 \%$ sensibility for women.

\section{Discussion}

In this study, NC correlated significantly with traditional anthropometric indicators of obesity such as BMI and WC. Also, NC correlated with cardiovascular risk factors and \%TBF. The performance of NC to identify IR was similar to WC in women and inferior to WC and BMI in men.

Several studies have shown that NC is an innovative and representative anthropometric measure of excess body fat or its abnormal distribution, and can be used to identify individuals with cardiovascular risk 11,12,13. Different mechanisms have been implicated in the correlation of NC and cardiovascular risk factors. One possible mechanism is that free fat acid storage process in the fed state favors upper-body fat accumulation in both sexes ${ }^{19}$. In addition, the increased release of free fatty acids from VF could be an important mechanism contributing to or leading to IR and endothelial 
Table 1

Characteristics of subjects according to gender. Niterói, State of Rio de Janeiro, Brazil.

\begin{tabular}{lccc}
\hline Characteristics & $\begin{array}{c}\text { Men }(\mathbf{n}=\mathbf{1 0 7}) \\
\text { Median (IQR) }\end{array}$ & $\begin{array}{c}\text { Women }(\mathbf{n}=\mathbf{3 0 4}) \\
\text { Median (IQR) }\end{array}$ & p-value * \\
\hline Age (years) & $69(64-74)$ & $70.5(65-76)$ & 0.33 \\
Neck circumference $(\mathrm{cm})$ & $39.7(37.3-41.5)$ & $33.5(31.9-35.5)$ & $<0.01$ \\
Body mass index $\left(\mathrm{kg} / \mathrm{m}^{2}\right)$ & $28.1(25.8-30.9)$ & $28(24.5-31.5)$ & 0.37 \\
Waist circumference $(\mathrm{cm})$ & $100.1(92.5-105.8)$ & $92.9(85.5-100.4)$ & $<0.01$ \\
Percentage of total body fat (\%) & $34.9(31.3-38.9)$ & $40.7(36.4-45.1)$ & $<0.01$ \\
Systolic blood pressure (mmHg) & $138.5(126.5-155.7)$ & $136(122.5-150.3)$ & 0.16 \\
Diastolic blood pressure (mmHg) & $79(71.2-84)$ & $74.5(66.6-80.5)$ & $<0.01$ \\
HDL-c (mg/dL) & $45(40-54)$ & $57(50-65)$ & $<0.01$ \\
Total cholesterol $(\mathrm{mg} / \mathrm{dL})$ & $188(165-214)$ & $205(179-234)$ & $<0.01$ \\
Triglycerides $(\mathrm{mg} / \mathrm{dL})$ & $131(96-184)$ & $119(91-155.7)$ & 0.31 \\
Fasting glucose $(\mathrm{mg} / \mathrm{dL})$ & $99(89.5-115.5)$ & $97(89-112)$ & 0.15 \\
Uric acid $(\mathrm{mg} / \mathrm{dL})$ & $4.5(3.8-5.4)$ & $3.7(2.9-4.6)$ & $<0.01$ \\
Fasting insulin $(\mu \mathrm{U} / \mathrm{L})$ & $10.1(7-18)$ & $9.3(6.5-16.4)$ & 0.49 \\
HOMA-IR & $2.6(1.8-5.3)$ & $2.4(1.6-4.3)$ & 0.27 \\
\hline
\end{tabular}

HDL-c: HDL-cholesterol; HOMA-IR: homeostasis model assessment insulin resistence index; IQR: interquartile range.

* Using the Mann-Whitney test.

Table 2

Correlations adjusted by age and diagnosis of diabetes among neck circumference (NC), body mass index (BMI), waist circumference (WC), and waist-hip ratio (WHR) with body composition analysis and cardiometabolic risk factors. Niterói, State of Rio de Janeiro, Brazil.

\begin{tabular}{|c|c|c|c|c|c|c|c|c|}
\hline \multirow[t]{3}{*}{ Variables } & \multicolumn{2}{|c|}{ NC } & \multicolumn{2}{|c|}{ BMI } & \multicolumn{2}{|c|}{ WC } & \multicolumn{2}{|c|}{ WHR } \\
\hline & Men * & Women ** & Men * & Women ** & Men * & Women ** & Men * & Women ** \\
\hline & $\mathbf{R}$ & $\mathbf{R}$ & $\mathbf{R}$ & $\mathbf{R}$ & $\mathbf{R}$ & $\mathbf{R}$ & $\mathbf{R}$ & $\mathbf{R}$ \\
\hline NC & 1.00 & 1.00 & $0.71 * * *$ & $0.72 * * *$ & $0.69 * * *$ & $0.66 * \star *$ & $0.45 * \star \star$ & $0.27 * \star \star$ \\
\hline BMI & $0.71 * \star \star$ & 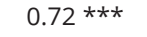 & 1.00 & 1.00 & $0.84 * \star *$ & 0.87 & $0.30 * \star \star$ & 0.20 \\
\hline WC & $0.69 * \star \star$ & $0.66 * \star \star$ & $0.84 * \star \star$ & $0.87 * \star \star$ & 1.00 & 1.00 & $0.74 * \star \star$ & $0.53 * \star \star$ \\
\hline WHR & $0.45 * \star \star$ & $0.27 * \star \star$ & $0.30 * \star *$ & $0.20 * * *$ & $0.74 * \star \star$ & $0.53 * \star \star$ & 1.00 & 1.00 \\
\hline$\%$ TBF & $0.42 * \star *$ & $0.54 * \star \star$ & $0.60 * \star *$ & $0.77 * * *$ & 0.58 & $0.46 * \star *$ & 0.43 & $0.18 * \star *$ \\
\hline SBP & 0.02 & 0.08 & 0.04 & 0.06 & 0.02 & 0.05 & -0.02 & 0.08 \\
\hline DBP & 0.26 & 0.07 & 0.09 & 0.07 & 0.06 & $0.13 * \star \star$ & -0.04 & $0.21 * \star \star$ \\
\hline HDL-C & $-0.29 * \star \star$ & $-0.20 * \star \star$ & $-0.29 * * *$ & $-0.31 * \star *$ & $-0.32 * \star *$ & $-0.25 * \star \star$ & -0.26 & $-0.28 * \star \star *$ \\
\hline $\mathrm{TC}$ & -0.08 & -0.04 & -0.01 & -0.05 & -0.06 & -0.06 & 0.02 & -0.07 \\
\hline TG & 0.18 & $0.26 * \star \star$ & $0.20 * * *$ & $0.23 * * \star$ & $0.27 * \star \star$ & $0.24 * \star \star$ & $0.31 * \star \star$ & $0.20 * * \star$ \\
\hline FPG & 0.03 & $0.22 * \star \star$ & 0.02 & $0.14 * * \star$ & 0.04 & $0.18 * \star \star$ & -0.01 & $0.14 * * *$ \\
\hline Uric acid & $0.26 * \star \star$ & $0.28 * * \star$ & $0.26 * * *$ & $0.30 * \star *$ & $0.30 * \star *$ & $0.29 * \star \star$ & $0.36 * \star \star$ & $0.12 * * \star$ \\
\hline Fasting insulin & $0.49 * \star \star$ & $0.46 * \star \star$ & $0.56 * \star \star$ & $0.50 * \star \star$ & $0.57 * \star \star$ & $0.55 * \star \star$ & $0.37 * \star \star$ & $0.38 * \star \star$ \\
\hline HOMA-IR & $0.44 * \star \star$ & $0.47 * \star \star$ & $0.50 * \star *$ & $0.48 * * *$ & $0.52 * \star *$ & $0.53 * \star \star$ & $0.37 * * \star$ & $0.37 * \star \star$ \\
\hline
\end{tabular}

\%TBF: percentage of total body fat; DBP: diastolic blood pressure; FBG: fast blood glucose; HDL-c: HDL-cholesterol; HOMA-IR: homeostasis model assessment insulin resistence index; R: Spearman's correlation partial adjusted by age and diagnosis of diabetes; SBP: systolic blood pressure;

TC: total cholesterol; TG: triglycerides.

* Men: $\mathrm{n}=107$;

** Women: $\mathrm{n}=304$

$* * *$ p-value $<0.01$ 
ROC (receiver operating characteristic) curves for body mass index (BMI), neck circumference (NC), waist circumference (WC), and waist-to-hip ratio (WHR) for the diagnosis of insulin resistance (homeostasis model assessment insulin resistence index: HOMA-IR) in women and men ( $p$-value < 0.001).

1a) ROC curve: women

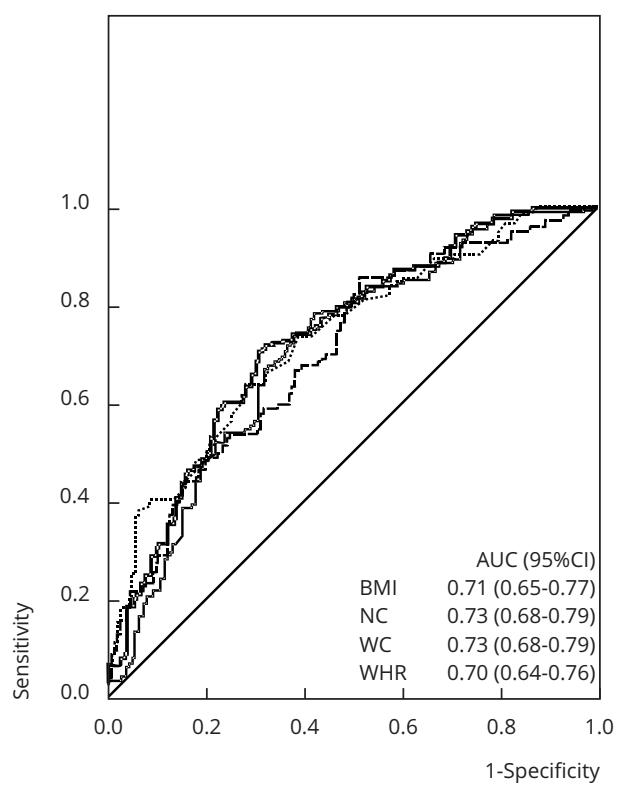

1b) ROC curve: men

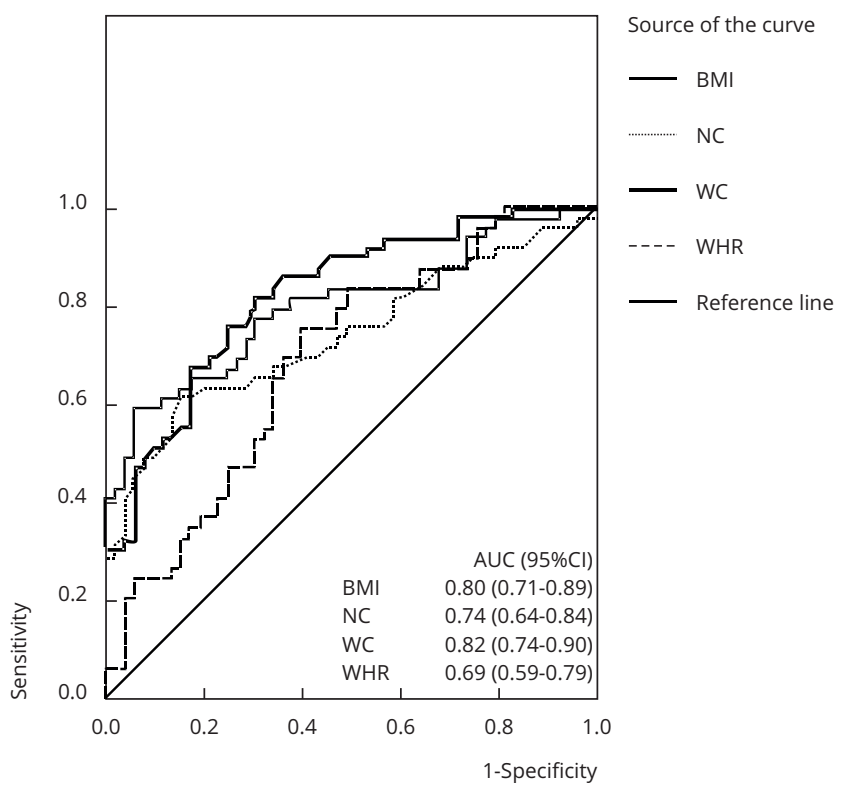

95\%Cl: 95\% confidence interval; AUC: area under the curve.

dysfunction 20, which would render the measure of $\mathrm{NC}$ as an important tool in identifying individuals with increased cardiovascular risk. In a study by Zhou et al. 21 , NC significantly correlated with all outcomes of cardiometabolic risk in both sexes.

In this study, NC showed a significant correlation with BMI, WC and WHR, similar to the study in Turkish adults with mean age of 55 years 22. In Brazilian young adults, a significant correlation between NC, BMI, WC, and WHR was also demonstrated 11.

Neck circumference, BMI, WC, and WHR were positively correlated with \%TBF, similar to previous studies that demonstrated significant correlation between NC and VF measured by CT or ultrasound 11,13. The bioimpedance analysis is a validated method with satisfactory sensitivity and specificity to predict VF in older population ${ }^{23}$. Li et al. ${ }^{24}$, comparing neck and lower abdomen CT areas, found significant correlation between NC and VF in Chinese adult men and women, what may be accounted by the fact that neck fat was significantly correlated with VF.

Considering the cardiovascular risk factors, NC was positively correlated with fasting blood glucose, TG, uric acid, fasting insulin, and HOMA-IR, while there was a negative correlation between NC and HDL-c, in accordance with previous studies 12,19,24. Several of these risk factors are components of the metabolic syndrome, which increases the risk of macrovascular disease 5,25.

This study showed a significant correlation between NC and IR, measured by HOMA-IR, in agreement with previous studies 24,26,27. Moreover, a previous analysis of the Framingham Heart Study demonstrated that NC is associated with IR, hypertension, and dyslipidemia, regardless of VF 12. Stabe et al. 11, using the same cut-off value for HOMA-IR in younger adults, showed that NC was the best anthropometric measure on the prediction of IR in women, similar to the results we found for older patients. 
Therefore, in addition to WC, NC could also be used as a simple, quick method for identifying insulin resistance, especially in the older population, who can present health conditions that affect the abdominal wall, organs, and cavity, as well as patients restricted to wheelchairs. NC, as an index of upper body obesity, can be used as a marker of IR in this population. This study has a few limitations, such as the small sampling size and the fact that the subjects were attending a primary care clinic. Also, the admixture of races in the Brazilian population may limit the external validity of these data to other populations. Further studies are necessary to identify the relationship between NC and cardiovascular risk factors in the general population.

\section{Conclusions}

This cross-sectional study conducted in the Southeast region of Brazil suggests that NC can predict insulin resistance, which is a marker of cardiovascular risk, in the older population attending a primary care center.

\section{Contributors}

M. A. N. Saad participated in the conception and design of the study; acquisition, analysis, and interpretation of data, drafting and critical revision of the intellectual content, final approval of the version to be published. M. L. G. Rosa contributed in the analysis and interpretation of data, drafting and critical revision of the intellectual content, final approval of the version to be published. G. B. Lima participated in the interpretation of data, critical revision of the intellectual content, final approval of the version to be published. R. A. Cruz Filho collaborated in the conception and design of the study, interpretation of data, critical revision of the intellectual content; final approval of the version to be published. All authors agreed to be accountable for all aspects of this study.

\section{Acknowledgments}

To the Municipal Health Foundation of Niterói for the financial support. 


\section{References}

1. Mello AC, Engstrom EM, Alves LC. Healthrelated and socio-demographic factors associated with frailty in the elderly: a systematic literature review. Cad Saúde Pública 2014; 30:1143-68.

2. Calle EE, Thun MJ, Petrelli JM, Rodríguez C, Heath Jr. CW. Body mass index and mortality in a prospective cohort of U.S. adults. N Engl J Med 1999; 341:1097-105.

3. Perissinotto E, Pisent C, Sergi G, Grigoletto F, Enzi G. Anthropometric measurements in the elderly: age and gender differences. Br J Nutr 2002; 87:177-86.

4. Wannamethee SG, Shaper AG, Morris RW, Whincup PH, Walker M. Overweight and obesity and the burden of disease and disability in elderly men. Int J Obes Relat Metab Disord 2004; 28:1374-82.

5. Zhou M, Offer A, Yang G, Smith M, Huj G, Whitlock G, et al. Body mass index, blood pressure, and mortality from stroke: a nationally representative prospective study of 212,000 Chinese men. Stroke 2008; 39:753-9.

6. Nicklas BJ, Cesari M, Penninx BW, Kritchevsky SB, Ding J, Newman A, et al. Abdominal obesity is an independent risk factor for chronic heart failure in older people. J Am Geriatr Soc 2006; 54:413-20.

7. Kuk JL, Katzmarzyk PT, Nichaman MZ, Church TS, Blair SN, Ross R. Visceral fat is an independent predictor of all-cause mortality in men. Obesity (Silver Spring) 2006; 14:336-41.

8. Shen W, Wang Z, Punyanita M, Lei J, Sinav A, Kral JG, et al. Adipose tissue quantification by imaging methods: a proposed classification. Obes Res 2003; 11:5-16.

9. Seidell JC, Visscher TL. Body weight and weight change and their health implications for the elderly. Eur J Clin Nutr 2000; 54 Suppl 3:S33-9.

10. Sorkin JD, Muller DC, Andres R. Longitudinal change in height of men and women: implications for interpretation of the body mass index. The Baltimore Longitudinal Study of Aging. Am J Epidemiol 1999; 150:969-77.

11. Stabe C, Vasques AC, Lima MM, Tambascia MA, Pareja JC, Yamanaka A, et al. Neck circumference as a simple tool for identifying the metabolic syndrome and insulin resistance: results from the Brazilian Metabolic Syndrome Study. Clin Endocrinol (Oxf) 2013; 78:874-81.

12. Dai Y, Wan X, Li X, Jin E, Li X. Neck circumference and future cardiovascular events in a high-risk population: a prospective cohort study. Lipids Health Dis 2016; 15:46.

13. Preis SR, Massaro JM, Hoffmann U, D’Agostino Sr. RB, Levy D, Robins SJ, et al. Neck circumference as a novel measure of cardiovascular risk: the Framingham Heart study. J Clin Endocrinol Metab 2010; 95:3701-10.

14. Lukaski HC, Bolonchuk WW, Hall CB, Siders WA. Validation of tetrapolar bioelectrical impedance method to assess human body composition. J Appl Physiol 1986; 60:1327-32.
15. Geloneze B, Vasques AC, Stabe CF, Pareja JC, Rosado LE, Queiroz EC, et al. HOMA 1-IR and HOMA 2-IR indexes in identifying insulin resistance and metabolic syndrome: Brazilian Metabolic Syndrome Study (BRAMS). Arq Bras Endocrinol Metabol 2009; 53:281-7.

16. Blaak E. Gender differences in fat metabolism. Curr Opin Clin Nutr Metab Care 2001; 4:499502.

17. Karastergiou K, Smith SR, Greenberg AS, Fried SK. Sex differences in human adipose tissues: the biology of pear shape. Biol Sex Differ 2012; 3:13.

18. Dancey C, Reidy J. Statistics without maths for psychology: using SPSS for Windows. London: Prentice Hall; 2004.

19. Facchini FS, Hua N, Abbasi F, Reaven GM. Insulin resistance as a predictor of age-related diseases. J Clin Endocrinol Metab 2001; 86:3574-8.

20. Koutsari C, Snozek CL, Jensen MD. Plasma NEFA storage in adipose tissue in the postprandial state: sex-related and regional differences. Diabetologia 2008; 51:2041-8.

21. Zhou J, Ge H, Zhu M, Wang L, Chen L, Tan Y, et al. Neck circumference as an independent predictive contributor to cardio-metabolic syndrome. Cardiovasc Diabetol 2013; 12:76.

22. Onat A, Hergenç G, Yüksel H, Can G, Ayhan E, Kaya Z, et al. Neck circumference as a measure of central obesity: associations with metabolic syndrome and obstructive sleep apnea syndrome beyond waist circumference. Clin Nutr 2009; 28:46-51.

23. Eickemberg M, Oliveira CC, Roriz AK, Fontes GA, Mello AL, Sampaio LR. Bioimpedância elétrica e gordura visceral: uma comparação com a tomografia computadorizada em adultos e idosos. Arq Bras Endocrinol Metab 2103; 57:27-32.

24. Li HX, Zhang F, Zhao D, Xin Z, Guo SQ, Wang $\mathrm{SM}$, et al. Neck circumference as a measure of neck fat and abdominal visceral fat in Chinese adults. BMC Public Health 2014; 14:311.

25. National Cholesterol Education Program (NCEP) Expert Panel on Detection, Evaluation, and Treatment of High Blood Cholesterol in Adults (Adult Treatment Panel III). Third Report of the National Cholesterol Education Program (NCEP) Expert Panel on Detection, Evaluation, and Treatment of High Blood Cholesterol in Adults (Adult Treatment Panel III) final report. Circulation 2002; 106:3143421.

26. Liang J, Teng F, Li Y, Liu X, Zou C, Wang Y, et al. Neck circumference and insulin resistance in Chinese Adults: the Cardiovascular Risk in Chinese (CRC) Study. Diabetes Care 2013; 36:145-6.

27. Wang X, Zhang N, Yu C, Ji Z. Evaluation of neck circumference as a predictor of central obesity and insulin resistance in Chinese adults. Int J Clin Exp Med 2015; 8:19107-13. 


\section{Resumo}

O presente estudo investigou a correlação da circunferência do pescoço $(C P)$ e outras medidas antropométricas com os fatores de risco cardiovasculares e resistência insulínica $(R I)$ em idosos de $\mathrm{Ni}$ terói, Rio de Janeiro, Brasil. Foi realizado estudo transversal com 411 pacientes na atenção primária de saúde. Medidas antropométricas como $C P$, indice de massa corporal (IMC), circunferência da cintura (CC) e razão cintura-quadril (RCQ) foram aferidas. A bioimpedância elétrica (BIA) estimou o percentual da gordura corporal total (\%GC). A resistência à insulina foi estimada pelo HOMA-IR (homeostasis model assessment IR index). Os dados foram analisados utilizando o teste de Mann-Whitney e a correlação entre as variáveis numéricas pelo teste de Spearman. A curva ROC (receiver operating characteristic) foi utilizada para avaliar a capacidade preditiva das medidas antropométricas no diagnóstico de RI. A $C P$ foi positivamente correlacionada com a CC, o IMC, RCQ, \%TBF e com o HOMA-IR em ambos os sexos. Nas mulheres, a CP apresentou a maior AUC (área sob a curva) para RI. Nos homens, a $C C$ apresentou a maior AUC, seguido pelo IMC e CP. O presente estudo realizado no Sudeste do Brasil sugere que a CP pode predizer a RI, importante marcador de risco cardiovascular, na população idosa atendida na atenção primária de saúde.

Antropometria; Doenças Cardiovasculares; Resistência à Insulina; Idoso

\section{Resumen}

El presente estudio investigó la correlación de la circunferencia del cuello (CP) y otras medidas antropométricas con los factores de riesgo cardiovasculares y resistencia a la insulina (RI) en ancianos de Niterói, Río de Janeiro, Brasil. Fue realizado estudio transversal con 411 pacientes en la atención primaria de salud. Medidas antropométricas como $C P$, indice de masa corporal (IMC), circunferencia de la cintura (CC) y razón cintura-cadera (RCC) fueron tomadas con precisión. La bioimpedancia eléctrica (BIA) estimó el porcentaje de la grasa corporal total (\%GC). La resistencia a la insulina se estimó por el HOMA-IR (homeostasis model assessment IR index). Los datos se analizaron utilizando el test de Mann-Whitney y la correlación entre las variables numéricas por el test de Spearman. La curva ROC (receiver operating characteristic) fue utilizada para evaluar la capacidad predictiva de las medidas antropométricas en el diagnóstico de RI. La CP fue positivamente correlacionada con la CC, el IMC, RCC, \%TBFy con el HOMA-IR en ambos sexos. En las mujeres, la CP presentó la mayor AUC (área bajo la curva) para $R I$. En los hombres, la CC presentó la mayor AUC, seguido por el IMC y CP. El presente estudio realizado en el sudeste de Brasil sugiere que la CP puede predecir la RI, importante marcador de riesgo cardiovascular, en la población anciana atendida en la atención primaria de salud.

Antropometría; Enfermedades Cardiovasculares; Resistencia a la Insulina; Anciano
Submitted on 09/Apr/2016

Final version resubmitted on 20/Jul/2016

Approved on 14/Oct/2016 